\title{
The visor flap: Preservation of length in finger amputations
}

\author{
Michael W Neumeister MD FRCSC, G Andrew Robertson MPhil FRCS FRCSC \\ Section of Plastic Surgery, University of Manitoba, Winnipeg, Manitoba
}

\section{MW Neumeister, GA Robertson. The visor flap: Preservation of length in finger amputations. Can J Plast Surg 1999;7(2):59-64.}

Finger amputations at various levels are common injuries. A wide variety of surgical procedures have been described to obtain closure of open finger wounds. Preservation of length, sensate padding and innocuous scars are among the important goals of finger amputation coverage to maintain adequate function of the injured hand. A new technique in closure of the transverse finger amputation is reported. The visor flap is a bipedicled dorsal flap that takes advantage of the dorsal branches of the volar digital neurovascular bundles to achieve the goals of closure for finger amputations.

Key Words: Amputations; Finger; Flaps; Visor flap

\section{Le lambeau en visière : Préservation de la longueur dans les amputations des doigts}

RÉSUMÉ : Les amputations des doigts à différents niveaux sont des blessures courantes. Plusieurs techniques chirurgicales ont été décrites pour parvenir au recouvrement des blessures ouvertes des doigts. La préservation de la longueur, un rembourrage conservant la sensation et des cicatrices anodines figurent parmi les objectifs importants du recouvrement de l'amputation d'un doigt pour que la main blessée puisse conserver une fonction adéquate. On présente le compte-rendu d'une nouvelle technique de recouvrement d'une amputation transverse du doigt. Le lambeau en visière est un lambeau dorsal bipédiculé qui tire avantage du paquet vasculo-nerveux palmaire digital pour atteindre les objectifs de recouvrement dans les amputations du doigt.

$\mathrm{M}$ ethods of closure of the amputated finger stump are legion. Certain levels of amputation, however, demand preservation of length for optimum function. The visor flap provides this, together with sensation, padding and scars that avoid volar pressure points. The design of the flap follows the principles of three-dimensional rather than plane geomery.

\section{PRINCIPLES OF FLAP DESIGN}

The visor flap is a bipedicled flap based on the dorsal branches of the volar digital neurovascular bundles (Figure 1). Transverse amputations of the distal, middle and distal proximal phalanges are most suitable for this technique. Figure 2 illustrates the design of the dorsal flap. The volar/dorsal diameter of the amputation site is measured (A-B). To achieve adequate coverage, a similar area of dorsal skin and subcuta-

Correspondence and reprints: Dr GA Robertson, Section of Plastic Surgery, Rm GC 413, Health Science Centre, 820 Sherbrook Street, Winnipeg, Manitoba R3A 1R9. Telephone 204-787-1485,

fax 204-787-4837, e-mail lmydynski@hsc.mb.ca neous tissue must be obtained $(\mathrm{A}-\mathrm{C})$, therefore, $\mathrm{A}-\mathrm{B}$ is equal to $\mathrm{A}-\mathrm{C}$. The extent of the lateral incisions are to the mid axial line (D). The pivot point, $\mathrm{D}$, restricts the volar transposition of this bipedicled flap because C-D is shorter than A-C. Therefore, a back cut (Figure 3 ) is made so that $\mathrm{A}-\mathrm{D}_{1}$ is equal to $\mathrm{C}-\mathrm{D}_{1}$. The new pivot point of $\mathrm{D}_{1}$ allows adequate volar transposition of the flap. The back cut must be through dermis only to avoid potential damage to the neurovascular structures in the subcutaneous plane.

The dissection is deepened down to but not through the paratenon level. The flap is undermined and transposed distally, and sutured with a nonabsorbable suture. The donor defect is covered with a split thickness skin graft and dressed appropriately: excess skin (dog ears) may be prominent laterally, but these should not be tailored because this may interfere with the neurovascular supply to the flap. Physiotherapy to maintain range of motion is initiated on postoperative day 7. Skin graft maturation and contraction aids in the resolution of the dog ears and acts as a force in drawing the volar scar dorsally, leaving a volar surface free of a potentially prominent and/or painful scar line. 


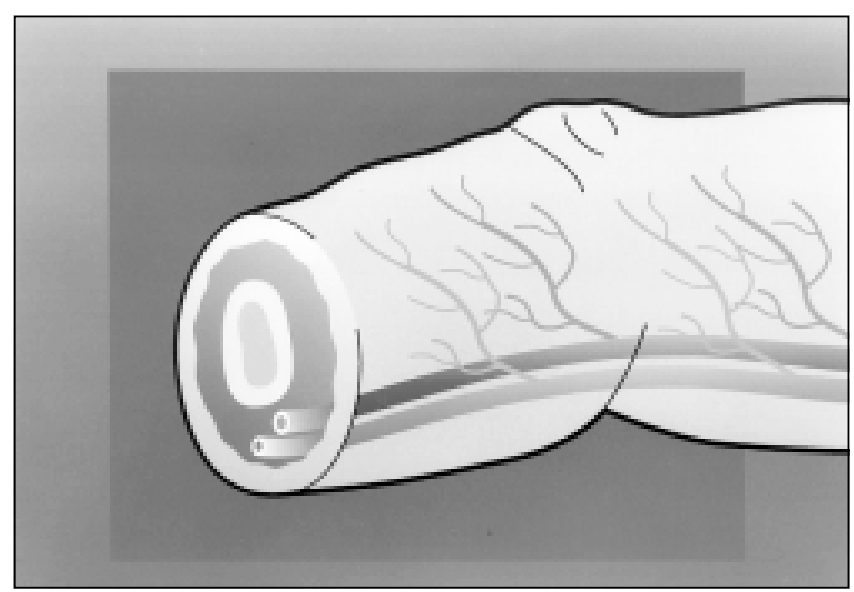

Figure 1) Neurovascular supply to the dorsum of the digit

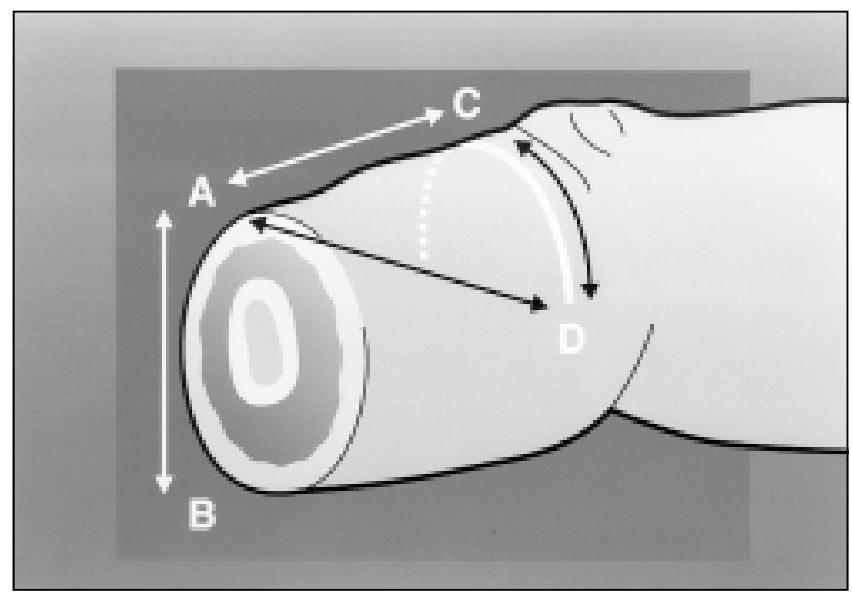

Figure 2) Flap design . A-B Diameter of defect; $A-C$ Equivalent width of flap; $D$ Pivot point (inadequate given the distance $A-D$ )

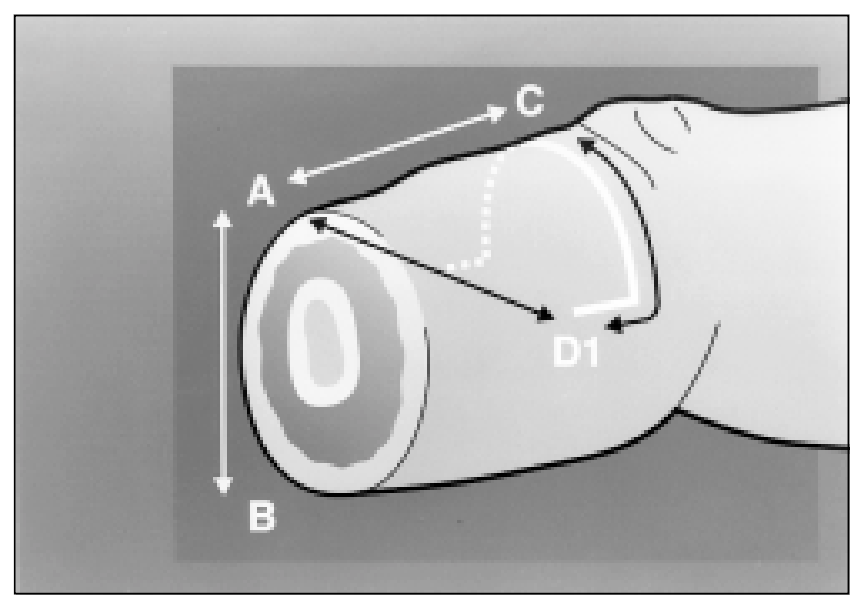

Figure 3) Importance of the backcut. A-B Diameter of defect; $A-C$ Equivalent width of flap; D Pivot point after backcut

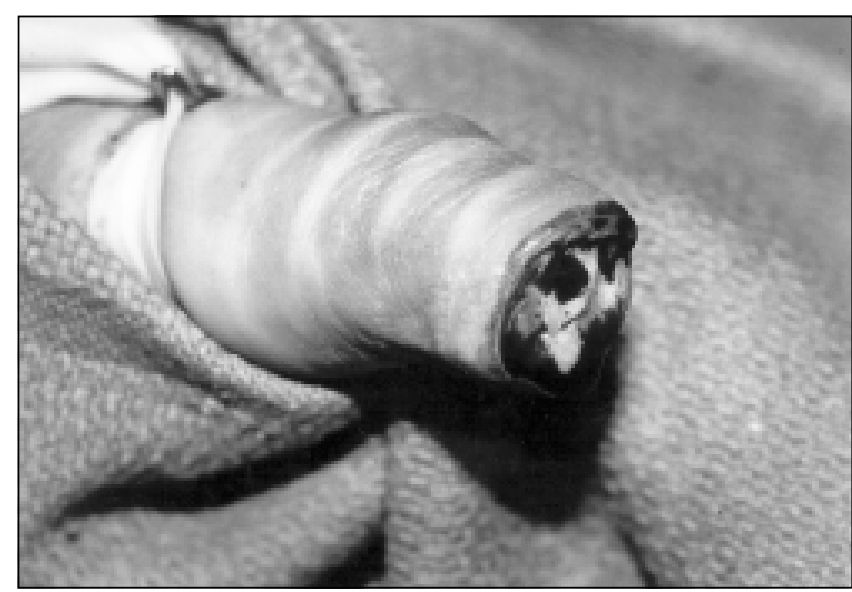

Figure 4) A transverse amputation of the right index finger at the level of the distal interphalangeal joint. The bone is flush with the wound. The dorsal skin at this level is supplied by the dorsal branches of the volar digital neurovascular bundles

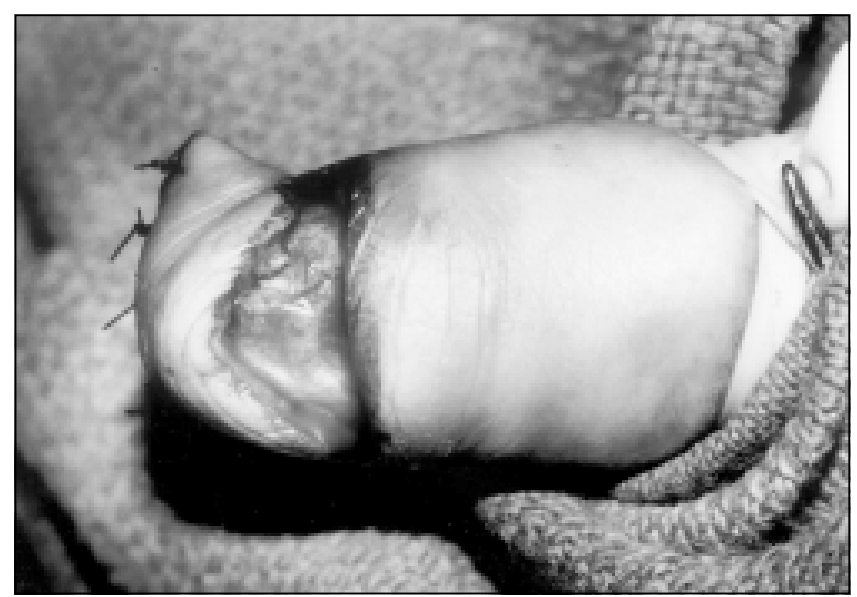

Figure 5a) The dorsal visor flap has been mobilized at the paratenon plane and transposed over the distal wound. The dog ears appear prominent at this stage

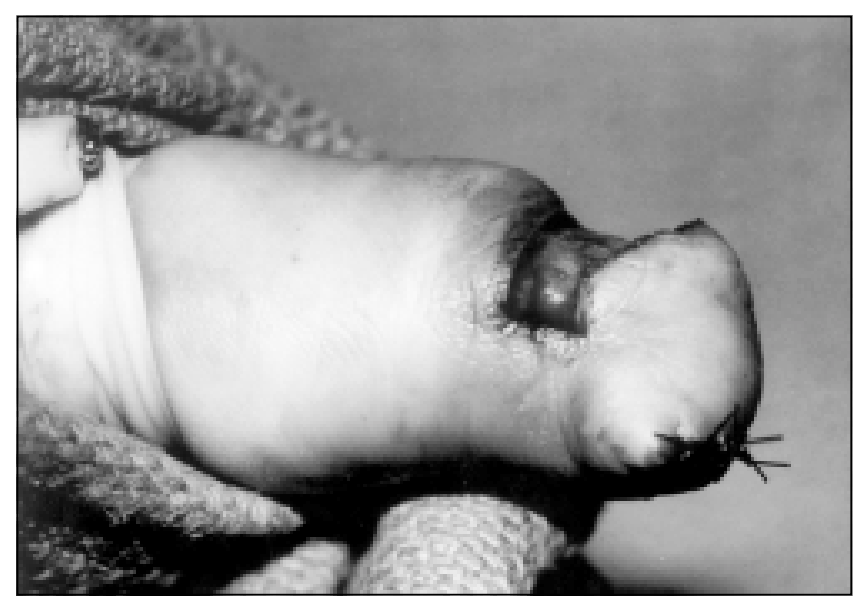

Figure 5b) Back-cut to allow adequate movement of the flap 


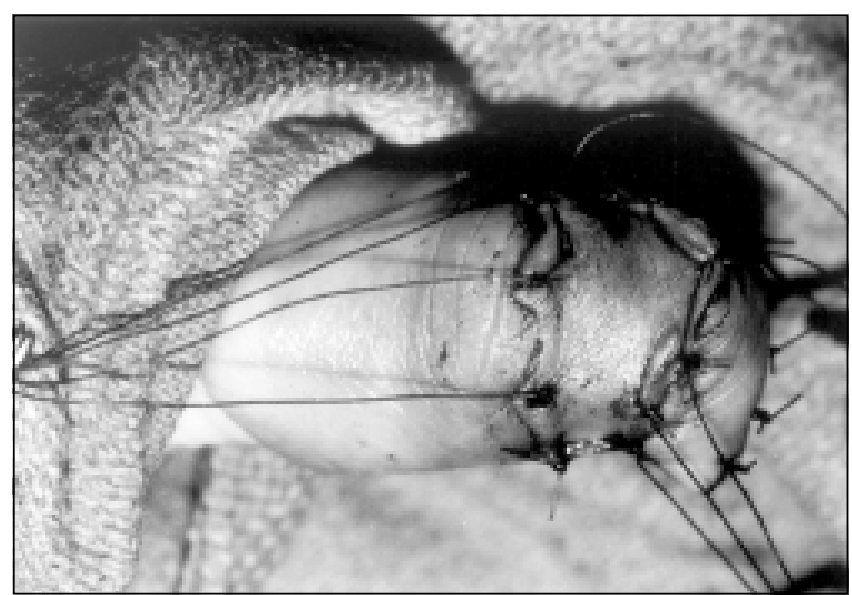

Figure 6a) A split thickness skin graft is contoured into place to cover the donor defect

\section{CASE PRESENTATIONS}

\section{Case 1}

A 32-year-old male sustained an amputation of the right index finger while working with a punch press. The amputation was transverse at the level of the distal interphalangeal joint. The bone was flush with the soft tissue (Figure 4). The distal amputation site was covered with a visor flap. The distal dorsal skin and soft tissue were transposed over the end of the stump, allowing for a sensate, well vascularized, padded covering (Figure 5a,b). A split thickness skin graft was applied to the dorsum of the skin layer at the donor defect (Figure 6a,b). The wounds were dressed for one week. At this time, motion of the proximal interphalangeal joint was commenced. Follow-up at one year showed a functional, cosmetically acceptable amputated stump of the index finger. Contracture of the split thickness skin graft pulled the volar scar dorsally away from the area of normal pressure. Dog ears similarly resolved with time (Figure 7).

\section{Case 2}

A 50-year-old male sustained multiple distal amputations of the fingers of his left hand as a result of a power saw accident. The amputated finger tips were traumatized. The amputation to the long, ring and little fingers were transverse and at the level of the distal middle phalanx (Figure 8). Visor flap closure was performed to provide maintenance of length, sensation and padding to the bone exposed distal finger amputations. The donor defect was grafted with a split thickness skin graft. At one year follow-up, the distal stump was well padded and free of dog ears, with normal sensation and a volar surface free of an incision scar (Figure 9).

\section{DISCUSSION}

Amputations of the fingers at various levels are common injuries. Less frequent, though, are amputations of the fingers that are amenable to replantation. If replantation of the amputated finger or finger remnant is not performed, a means of revision amputation for closure is necessary. Many closures

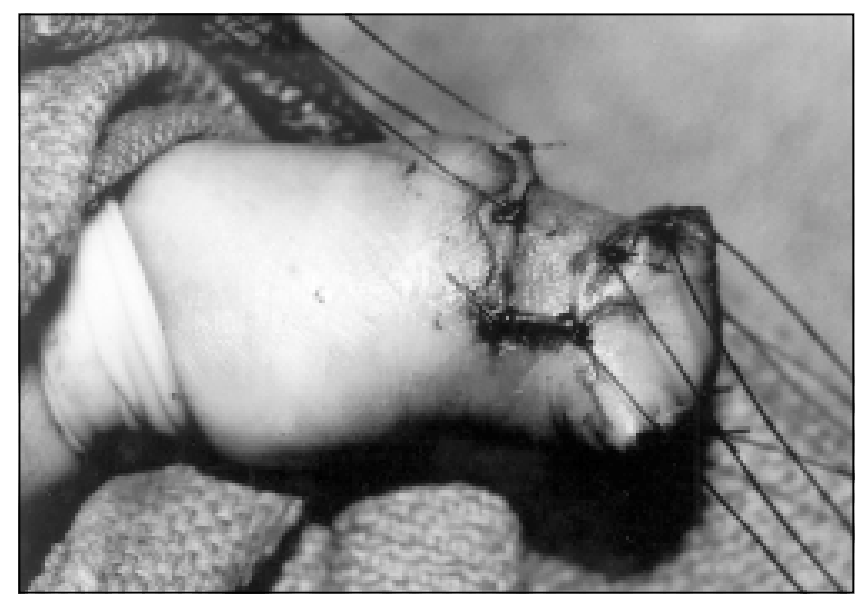

Figure 6b) A lateral view of the graft on the paratenon bed

of amputations have been described. These procedures depend on a number of factors including the finger involved, the level of amputation injury, the angle of the amputation, whether bone is exposed and the viability of adjacent tissue. In these amputations, where there is enough soft tissue available, direct closure can be achieved (1). Alternatively, if soft tissue is covering the bone and a skin defect exists, then the wound can be grafted or allowed to heal via secondary intentions (2). These are common and acceptable means of obtaining wound coverage and closure where bone is not exposed.

If the bone is exposed, further assessment and treatment are required to obtain wound closure. A simple and effective means of achieving this goal is to remove the distal exposed bone to a point where direct closure of the wound can occur. This allows for a well padded, sensate amputation stump. Many have advocated that this procedure for index finger injuries can be the treatment of choice because the loss of length may not alter function significantly, and the patient can undergo immediate rehabilitation. Preservation of length, however, is important in improving grip strength by acting as a longer lever. This may be true in all fingers, particularly the ulnar three digits.

There have been many descriptions of length-preserving procedures in finger amputations. With bone exposed, local, regional, distal and even free flaps have been used to achieve coverage and closure. Atasoy et al (3), Kutler (4), and Venkataswami and Subramanian (5) have described V-Y advancements, either with volar tissue or lateral tissue to close the distal amputations. Atasoy flaps are best used to treat the dorsal oblique amputations. Bilateral Kutler flaps can advance over angled and transverse distal amputations. A volar scar, however, is common to each of these local flaps. This scar is not infrequently a source of ongoing discomfort on the pressure points of the distal volar finger. Step advancement flaps are neurovascularly intact and require meticulous dissection, achieving similar goals and outcomes as the Kutler flaps (6).

Other local flaps include the Ogo (7) and Flint/Harrison (8) flaps, which use the dorsal skin of the finger for coverage. The Ogo flap is an unipedicled, laterally based flap, trans- 

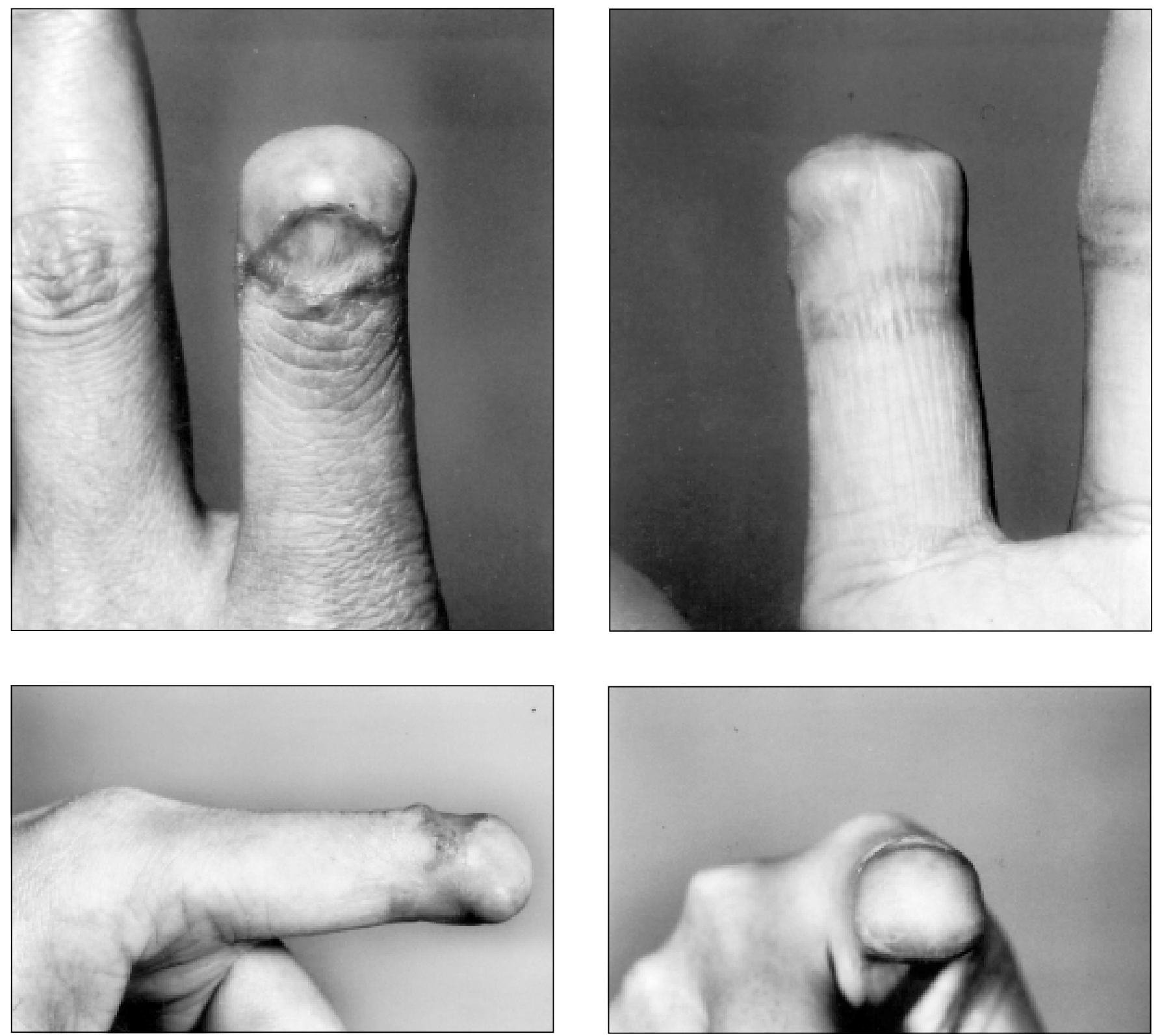

Figure 7) One-year follow-up of the finger amputation covered with the visor flap. The dog ears have resolved. The contraction of the skin graft has pulled the volar scar to a more dorsal site off the pressure points of the finger pad. A well padded, sensate amputation stump is observed

posed from dorsum to distal amputation site. The donor site is then grafted. This flap does not maintain sensation, and the distal vascularity may be somewhat precarious. The Flint/ Harrison flap is similar, but is based more proximally and can retain the neurovascular supply, thereby maintaining sensation. This flap, too, may have a limited distal vascularity.

Cross-finger flaps (9) and thenar flaps $(10,11)$ have worked well for coverage, but, again, are not sensate and may interfere with the function of the other fingers or hand because of stiffness or pain. Modifications to the cross-finger flap have incorporated dorsal digital nerves, which are subsequently anastomosed with the volar nerves to achieve a sensate flap (12). These cross-finger, thenar and distant flap procedures require appropriate patient compliance and may be somewhat cumbersome.
Neurovascular island flaps using tissue from adjacent fingers can also be useful in providing sensate coverage $(13,14)$. Similarly, the reverse digital artery flap from the lateral proximal phalanx uses the volar digital neurovascular supply of one side of the finger to provide vascularity and sensation to the flap and, hence, the recipient $(15,16)$. These flaps also require meticulous dissection. More important, the patient may have serious problems due to persistent identification of sensation from the donor rather than the recipient site.

Free pulp transfer has been described for coverage of the distal finger amputations with appropriate neurovascular reconstruction (17-19). This can provide appropriate sensate coverage. Volar scars may still be present. Of more significance, the patient must undergo a lengthy operation and ex- 


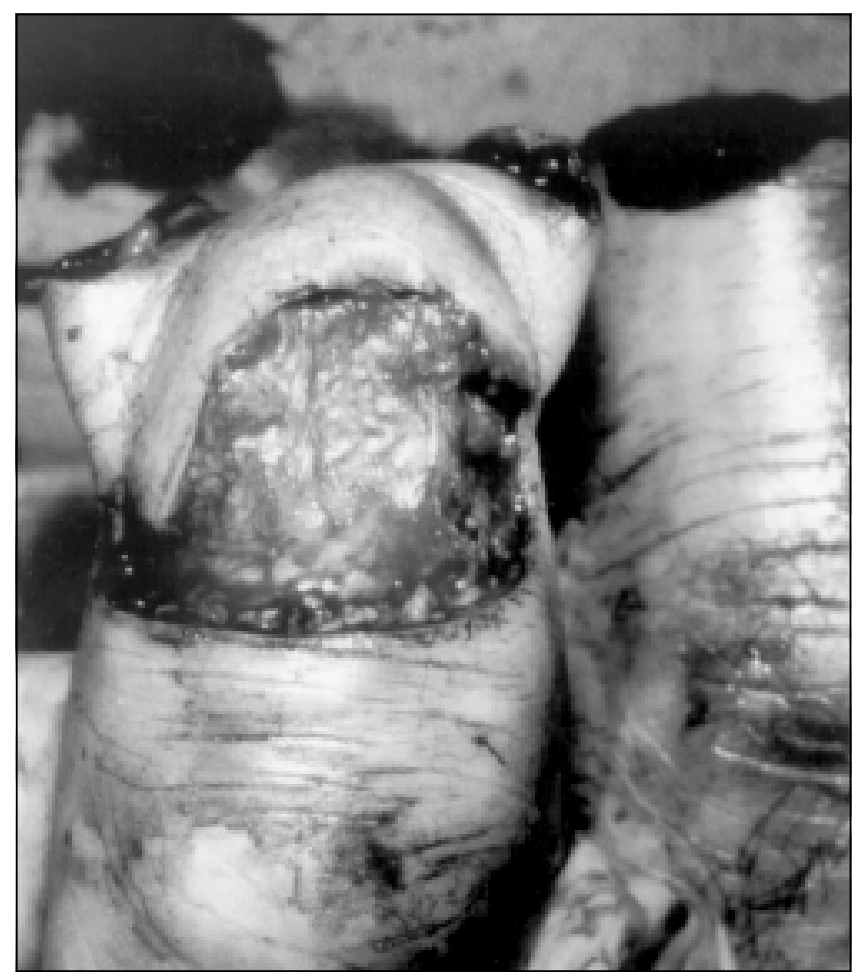

Figure 8) Amputation of the long, ring and little fingers at the middle phalangeal joint. The visor flap has been transposed distally on the long finger

tensive hospital stay. This also requires microsurgical expertise, specifically notable for the small distal diameter of the distal digital vessels and nerves.

The visor flap was designed to address the goals of distal finger amputations. Length, sensate, vascularized padding and minimal volar scars are preserved with this procedure. The visor bipedicled flap is applicable for transverse amputations of the fingers taking advantage of the dorsal branches of the volar digital nerves and vessels (16). This reliable flap can be easily executed under local anesthesia in an adequately equipped emergency department, allowing the patient to be discharged immediately. After one week, mobilization of the digits is started to prevent stiffness in the remaining joints. As time progresses, the skin graft on the dorsum of the finger contracts, the dog ears are eliminated and the volar scars migrate dorsally.

The benefits of preservation of the bone length have been discussed above. It should be recognized, though, that preserving very small distal bony segments (close to the joints) may result in untoward flexion deformity. These cases may be best served by resecting this bony segment and allowing for primary closure.

The visor flap is introduced to provide the hand surgeon with an attractive alternative for coverage of transverse amputations of the middle and distal phalanges and can be considered for the more distal level of proximal phalangeal amputations.
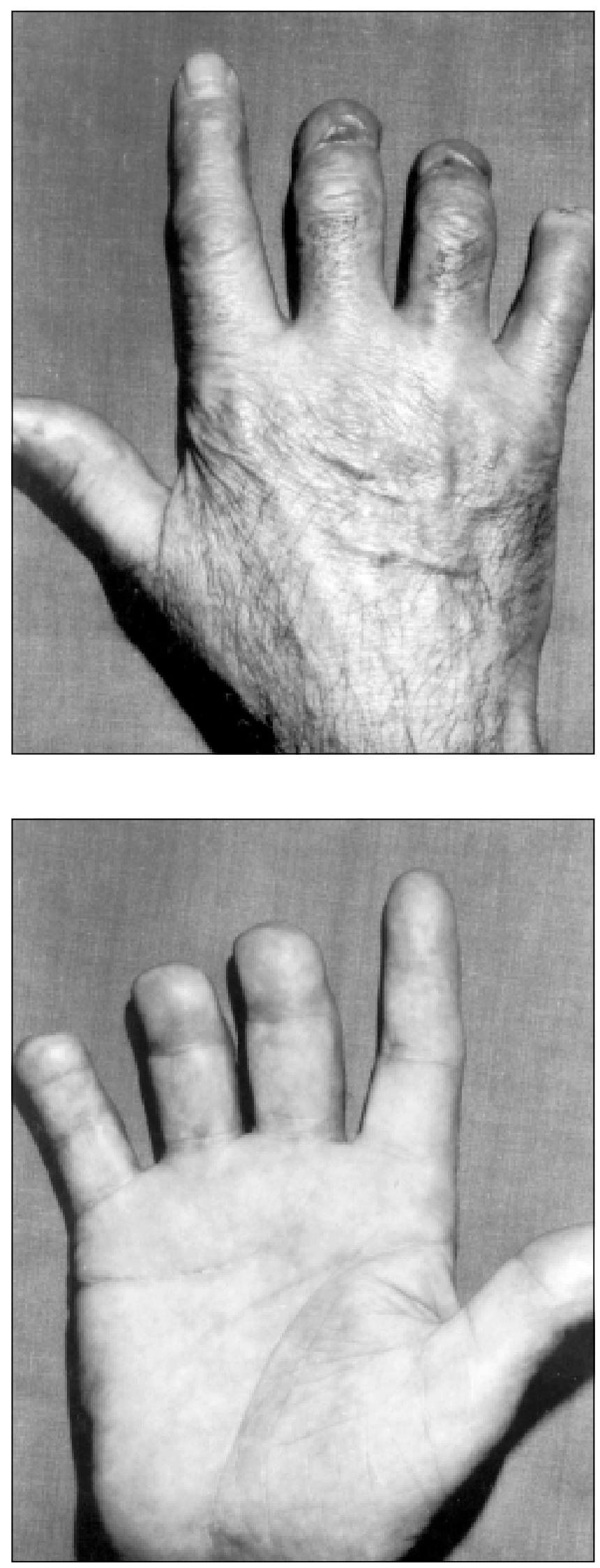

Figure 9) Top and bottom. Two-year follow-up of the long, ring and little finger amputation. The stumps are rounded and well padded, and length is preserved. No revisions have been performed 


\section{REFERENCES}

1. Russell RC, Casas LA. Management of fingertip injuries. Clin Plast Surg 1989;16:405-25.

2. Louis DS, Palmer AK, Burney RE. Open treatment of digital tip injuries. JAMA 1980;244:697-8.

3. Atasoy E, Ioakimidis E, Kasdan ML, Kutz JE, Kleinert HE. Reconstruction of the amputated finger tip with a triangular volar flap. J Bone Joint Surg 1970;52:921-6.

4. Kutler W. A new method for finger tip amputation. JAMA 1947;133:29-30.

5. Venkataswami R, Subramanian N. Oblique triangular flap: a new method of repair for oblique amputations of the fingertip and thumb. Plast Reconstr Surg 1980;66:296-300.

6. Evans DM, Martin DL. Step-advancement island flap for fingertip reconstruction. Br J Plast Surg 1988;41:105-11.

7. Ogo K, Ono N, Tsuchida Y, et al. Why a cross finger flap? An extended use of the homodigital finger dorsum flap. Proceedings of the 8th International Congress of Plastic and Reconstructive Surgery. Montreal, 1983.

8. Flint MH, Harrison SH. A local neurovascular flap to repair loss of the digital pulp. Br J Plast Surg 1965;18:156-63.

9. Gurdin M, Pangman WJ. Repair of surface defects of fingers by transdigital flaps. Plast Reconstr Surg 1950;5:368-71.
10. Smith RJ, Albin R. Thenar "H-flap" for fingertip injuries. J Trauma 1976;16:778-81.

11. Dellon AL. The proximal inset thenar flap for fingertip reconstruction. Plast Reconstr Surg 1983;72:698-704.

12. Cohen BE, Cronin ED. An innervated cross-finger flap for fingertip reconstruction. Plast Reconstr Surg 1983;72:688-97.

13. Littler JW. Neurovascular pedicle transfer of tissue. J Bone Joint Surg 1956;38:917.

14. Joshi BB. A local dorsolateral island flap for restoration of sensation after avulsion injury of fingertip pulp. Plast Reconstr Surg 1974;54:175-82.

15. Lai CS, Lin SD, Yang CC. The reverse digital artery flap for fingertip reconstruction. Ann Plast Surg 1989;22:495-500.

16. Lai CS, Lin SD, Chou CK, Tsai CW. A versatile method for reconstruction of finger defects; reverse digital artery flap. Br J Plast Surg 1992;45:443-53.

17. Chen CT, Wei FC, Chen HC, Chuang CC, Chen HT, Hsu WM. Distal phalanx replantation. Microsurgery 1994;15:77-82.

18. Foucher G, Norris RW. Distal and very distal digital replantations. Br J Plast Surg 1992;45:199-203.

19. Ishikura N, Tsukuda S. An easy method of vascular anastomosis for replantation of finger tips. J Reconstr Microsurg 1995;11:141-3. 